\title{
ESCRITA, DOUTRINA E ESQUECIMENTO: KAFKA E BENJAMIN
}

\author{
Romero Freitas
}

UFOP

\begin{abstract}
RESU MO
Qual o significado da escrita no motivo benjaminiano da história como salvação do passado? No ensaio sobre Kafka (1934), o problema do caráter estético da escrita da história alia-se à questão do valor de verdade ("doutrina") da literatura de ficção. Entre ambos, esboça-se uma dialética entre memória e esquecimento, na qual a escrita faz da narrativa uma espécie de memória que, agindo contra si mesma, atinge o "mar do feliz esquecimento".
\end{abstract}

\section{PALAVRAS - CHAVE}

Benjamin, Kafka, Escrita, Doutrina, Memória, Esquecimento.

\begin{abstract}
A criança está doente. A mãe a leva para a cama e senta-se junto a ela. E então começa a lhe contar histórias. Como se entende isso? Eu o pressentia, quando N. me falava do singular poder de cura que havia nas mãos de sua mulher. Mas ele dizia dessas mãos: "Seus movimentos eram altamente expressivos. Mas não se poderia descrever a sua expressão... Era como se ela contasse uma história." A cura por meio da narração nós já conhecemos, a partir das fórmulas mágicas de Merseburg. [...] Também se sabe como a narração que o doente faz ao médico no princípio do tratamento pode transformar-se no início de um processo de cura. [...] Se pensamos a dor como uma barragem que se opõe à corrente da narrativa, então vemos claramente que ela romperá onde a inclinação tornar-se suficientemente forte para levar tudo aquilo que a corrente encontra nesse caminho ao mar do feliz esquecimento. $\mathrm{O}$ acariciar desenha um leito para essa corrente. ${ }^{1}$
\end{abstract}

Benjamin intitulou esse fragmento "Narração e Cura" (1932). Lido em conjunto com outros textos de sua obra, esta pequena imagem-de-pensamento (Denkbild) não trata apenas do cuidado materno, da anamnese médica e da rememoração ritual, mas também da literatura contemporânea, da historiografia e da escrita filosófica.

A imagem do rio é um antigo símile para a narrativa. No caso presente, um rio caudaloso pode ser imaginado a partir do ritmo da última frase. A referência às mãos e ao acariciar pode ser lida como o traço "aurático" da narrativa, tal como Benjamin o descreveu

${ }^{1}$ BENJAMIN, Walter. Gesammelte Schriften IV-1. Frankfurt (M): Suhrkamp, 1991, p. 430. Todas as traduções, salvo indicação em contrário, foram feitas pelo autor. 
extensamente em "O Narrador" (1936). Mas o curioso nesse fragmento é o fato de que esse rio só chega ao seu destino se for detido. Sem a dor a oferecer-lhe uma resistência, ele escoaria de modo improdutivo. Ele chegaria ao mar, mas esse mar não seria um feliz esquecimento; a dor permaneceria intocada, ficaria à margem da narrativa. Eis um primeiro ponto, que devemos ter em mente: para Benjamin, uma narrativa que flui sem obstáculos equivale a uma forma de evasão. Se, porém, o rio e a barreira se enfrentam, a verdadeira tarefa da narrativa se realiza. $\mathrm{O}$ ato de narrar, que é inicialmente um trabalho da memória, revela então o seu fim último: o esquecimento.

No âmbito histórico, isso mostra como Benjamin está distante da velha idéia de "resgatar o passado", ainda hoje dominante nos discursos oficiais. A memória, para ele, não funciona simplesmente como uma tradição, nem mesmo se pensarmos a idéia de tradição do modo mais interessante, isto é, como algo que se auto-transforma. A memória na verdade visa algo que vai além de si mesma, porque pretende aniquilar a si mesma. Em outras palavras, o que Benjamin propõe é uma dialética entre narrar, salvar e esquecer. Eis o que se pretende mostrar aqui, por meio de uma leitura dos textos benjaminianos que tratam daquilo que constitui a tarefa da escrita em Kafka. ${ }^{2}$

No pensamento contemporâneo, a onipresença do tempo e a multiplicação das formas de linguagem fizeram da escrita uma temática central. A ontologia já não pode descartá-la como se fosse apenas a parte mundana de um processo de ascese, como uma escada que se joga fora, após a conquista da verdade. No caso específico da obra de Benjamin, a questão da escrita assumiu uma importância singular: estando presente nos registros epistemológico e ontológico, como em Paul Veyne e Paul Ricoeur, ela habita ao mesmo tempo o domínio político, como em Claude Lefort. Um único motivo - a escrita da história como salvação do passado - é capaz de abrigar essas três dimensões.

Sob esse aspecto, a leitura benjaminiana de Kafka é exemplar. Comecemos pela questão do gesto, que domina toda a segunda parte do ensaio de 1934 ("Franz Kafka - A Propósito do Décimo Aniversário de sua Morte"). O mundo kafkiano será aí comparado a um "teatro do mundo", ${ }^{3}$ numa evidente alusão à poética do barroco. O ponto de partida dessa analogia será o "teatro ao ar livre de Oklahoma", ${ }_{4}^{4}$ que aparece no romance América. Como nesse estranho teatro todos podem ser contratados, Benjamin o identifica ao teatro do mundo. A contratação não será regida pelo critério da capacidade enquanto ator. Cada um deve representar apenas a si mesmo, pois os atores são aqui os seres humanos na sua integralidade, isto é, os personagens de um teatro cósmico, natural.

\footnotetext{
${ }^{2}$ Sobre a leitura benjaminiana de Kafka, veja-se: GAGNEBIN, Jeanne-Marie. História e narração em Walter Benjamin. São Paulo: Companhia das Letras, 1994; DEURING, Dagmar. Vergiss das Beste nicht!. In: Walter Benjamins Kafka-Essay: Leben, Schreiben, Erfahren. Würzburg: Königshausen/Neumann, 1994; MÜLLER, Bernd. Denn es ist noch nicht geschehen. In: Walter Benjamins Kafka-Deutung. Köln: Böhlau, 1996.

${ }^{3}$ BENJAMIN, Walter. Gesammelte Schriften II-2. Frankfurt (M): Suhrkamp, 1991, p. 422.

${ }^{4}$ Ibidem, p. 417.
} 
Se pensarmos na analogia barroca entre teatro e mundo, como na peça O Grande Teatro do Mundo, de Calderón, perceberemos logo uma diferença essencial entre esse imaginário do século XVII e o mundo ficcional de Kafka. Nessa peça escrita em torno de 1635, o personagem "Autor" dá início à ação, "com manto de estrelas e resplendor na cabeça", ao invocar o "Mundo" e exortá-lo a lhe oferecer um culto:

Seremos, eu, o Autor, pois, neste instante, tu, o teatro, e o homem, recitante. ${ }^{5}$

O teatro do mundo kafkiano, por sua vez, não possui um Autor que possa ser conhecido. Pode-se dizer que ele é menos um teatro comandado por Deus do que um teatro cósmico. Mas, para tanto, será preciso acrescentar que, se esse cosmos não é o dos teólogos cristãos, também não devemos confundi-lo com o da ciência newtoniana. Ele não é regido por nenhuma lei conhecida, seja ela científica ou mítica. É nesse sentido que a leitura de Benjamin sempre se distancia da interpretação de Max Brod, que procurava apresentar Kafka ora como uma espécie de santo ${ }^{6}$, ora como o criador de uma nova forma de literatura teológica?

O teatro do mundo é o lugar em que o gesto assume o primeiro plano. Isso havia acontecido no teatro expressionista, que neste momento é lembrado pelo próprio Benjamin ${ }^{8}$. De um modo semelhante ao do palco expressionista, que utiliza procedimentos como máscaras e mímicas para romper com a ilusão de realidade buscada pelo naturalismo ${ }^{9}$, no texto de Kafka a centralidade do gesto tem o significado principal de interromper o fluxo dos acontecimentos, criando uma ocasião para o pensamento:

Uma das mais significativas funções desse teatro ao ar livre é a dissolução dos acontecimentos no elemento gestual. De fato, pode-se ir mais longe e dizer que um grande número dos estudos e histórias menores de Kafka só aparecem em sua luz plena na medida em que são como que transpostos em cenas no teatro ao ar livre de Oklahoma. ${ }^{10}$

A ênfase no gesto é realizada através de imagens. Benjamin apresenta uma série de imagens enigmáticas em Kafka, como, por exemplo, um fragmento da cena da conversa na catedral em O Processo:

Junto aos primeiros bancos ele parou, mas a distância ainda parecia grande demais para o sacerdote, que estendeu a mão e, com o indicador severamente inclinado para baixo, apontou pra um lugar logo à frente do púlpito. K. obedeceu também a isso; naquele lugar, tinha de curvar a cabeça bem para trás, para ainda ver o sacerdote. ${ }^{11}$

${ }^{5}$ CALDERÓN. O Grande Teatro do Mundo. Trad. Maria de Lourdes Martini. Rio de Janeiro: Francisco Alves, 1998, p. 3.

${ }^{6}$ BENJAMIN, Walter. Gesammelte Briefe VI. Frankfurt (M): Suhrkamp, 2000, p 106.

${ }^{7}$ BENJAMIN, Walter. Gesammelte Schriften II-2. Frankfurt (M): Suhrkamp, 1991, p. 426.

${ }^{8}$ Ibidem, p. 419.

${ }^{9}$ RÜHLE, Günter. Theater in unserer Zeit. Frankfurt (M): Suhrkamp, 1980, p. 14-15.

${ }^{10}$ BENJAMIN, Walter. Gesammelte Schriften II-2. Frankfurt (M): Suhrkamp, 1991, p. 418.

${ }^{11}$ KAFKA, Franz. O Processo. Trad. Modesto Carone. São Paulo: Companhia das Letras, 1998, p. 257. 
O característico dessas imagens é que a apresentação enfática de um gesto usualmente sem importância, como o ato de subir uma escada ${ }^{12}$, atrai a atenção do leitor de modo a suspender o fluxo convencional da narrativa, suscitando uma interrogação sobre o sentido dessas descrições. O sentido, porém, não se oferece docilmente ao leitor, como também não é uma posse segura do autor. Segundo Benjamin, "toda a obra de Kafka apresenta um código de gestos, que de modo algum possuem uma significação segura para o autor desde o início."13 Desse modo, os gestos rigorosamente codificados do teatro oriental dão lugar, na sua versão ocidental contemporânea, a uma espécie de codificação oculta, dificilmente acessível.

Como na teoria brechtiana do estranhamento ou distanciamento (Verfremdung), também estudada por Benjamin ${ }^{14}$, os gestos que interessam aqui são aqueles que desestabilizam o fluxo "normal" da ação. Esses gestos especiais invertem a relação usual entre primeiro e segundo planos: passam de imperceptíveis ações cotidianas, que deveriam apenas compor o quadro da ação principal, a objeto central da atenção do leitor. Por isso, Benjamin afirma que cada gesto é "um drama em si" que se desenvolve no palco do mundo, tendo o céu como pano de fundo. Mas essa pintura de cenário representa um céu despedaçado, como em El Greco, "padroeiro dos expressionistas"15.

Mas se não há um céu que justifique a ação apresentada no palco do mundo, onde se deve buscar o significado dos gestos? Se os textos de Kafka são alegóricos, como sugere a idéia de uma codificação oculta, em que lugar devemos procurar esse outro a que toda alegoria deve remeter?

Como já observou Jeanne-Marie Gagnebin ${ }^{16}$, o paradoxo da leitura benjaminiana de Kafka resulta da tentativa de uma interpretação "doutrinal" sem que se alcance qualquer forma positiva de doutrina. É dessa forma que Benjamin pretende ser fiel à ambição especificamente literária de Kafka. Mas isso significa, ao mesmo tempo, estabelecer um vínculo intrínseco, mesmo que discreto, entre literatura e política. A via estreita percorrida pela interpretação benjaminiana só se torna visível quando percebemos que os gestos e imagens que interrompem a narrativa apontam para um domínio simultaneamente estético e político. Uma indicação importante a esse respeito encontra-se numa breve comparação entre Kafka e Lukács:

Georg Lukács disse uma vez: para construir hoje uma mesa decente um homem precisa ter o gênio arquitetônico de Miquelângelo. Enquanto Lukács pensa em idades do tempo [Zeitaltern], Kafka pensa em idades do mundo [Weltaltern] ${ }^{17}$

\footnotetext{
${ }^{12}$ Veja-se, por exemplo, o início do conto "O novo advogado": "Temos um novo advogado, o dr. Bucéfalo. Seu exterior lembra pouco o tempo em que ainda era o cavalo de batalha de Alexandre da Macedônia. Seja como for, quem está familiarizado com as circunstâncias percebe alguma coisa. Não obstante, faz pouco eu vi na escadaria até um oficial de justiça muito simples admirar, com o olhar perito do pequeno freqüentador habitual das corridas de cavalos, o advogado quando este, empinando as coxas, subia um a um os degraus com um passo que ressoava no mármore." KAFKA, Franz. Um médico rural. São Paulo, Companhia das Letras, 1989, p. 11.

${ }^{13}$ BENJAMIN, Walter. Gesammelte Schriften II-2. Frankfurt (M): Suhrkamp, 1991, p. 418.

${ }^{14}$ BENJAMIN, Walter. O que é Teatro Épico? (Duas versões: 1931 e 1939). In: Gesammelte Schriften II-2. Frankfurt (M): Suhrkamp, 1991, p. 519-539.

${ }^{15}$ BENJAMIN, Walter. Gesammelte Schriften II-2. Frankfurt (M): Suhrkamp, 1991, p. 419.

${ }^{16}$ GAGNEBIN, Jeanne-Marie. História e Narração em Walter Benjamin. São Paulo: Companhia das Letras, 1994, p. 79-80.

${ }^{17}$ BENJAMIN, Walter. Gesammelte Schriften II-2. Frankfurt (M): Suhrkamp, 1991, p. 410.
} 
Eis aqui uma primeira pista: é através da oposição entre um eixo histórico-linear e outro cósmicoatemporal que se deve entender o espaço em que Kafka procura o significado dos gestos.

De início, essa dimensão cósmico-sincrônica deve ser reconhecida como aquela do destino, de acordo com a formulação desse conceito pelo filósofo Hermann Cohen ${ }^{18}$. A culpa de Josef K. em O Processo é como que decretada por uma potência anterior tanto a ele quanto ao tribunal. É isso que nos permite compreender como K. pode ser simultaneamente inocente em termos factuais - como se lê na primeira frase do romance: "Alguém certamente havia caluniado Josef $\mathrm{K}$. pois uma manhã ele foi detido sem ter feito mal algum" ${ }^{19}$ - e portador de uma culpa efetiva, embora desconhecida de todos. Donde uma de suas inquietantes reflexões: "faz parte do modo de procedimento dessa justiça o fato de que alguém é condenado não apenas inocentemente, mas também sem conhecimento." 20

A partir da idéia de destino em Hermann Cohen, que Benjamin combina com as especulações de Bachofen sobre a pré-história, a culpa do anti-herói kafkiano pode ser vista como algo que precede o domínio do humano propriamente dito, por ser anterior ao surgimento de um sistema de proibições e transgressões correspondentes. $\mathrm{O}$ agente só teria a experiência da Lei, portanto, da linguagem e da sua humanidade, depois que essa interdição inicial já foi transgredida. No mundo de Kafka, é como se a anomia de uma ordem social caótica, "incestuosa", se generalizasse: antes da Lei, as criaturas em geral estão misturadas, desconhecem o limite que deveria separá-las umas das outras. É por isso que o mundo de Kafka é atravessado por criaturas como o inseto-caixeiro-viajante (A Metamorfose), o advogado-cavalo ("O Novo Advogado"), a ratinha-cantora ("Josefine a Cantora ou O Povo dos Ratos”), o gato-carneiro (“Um Cruzamento") e o macaco-gentleman ("Relatório a uma Academia”); é por isso que Leni, n'O Processo, terá uma membrana ligando os dedos da mão; e, no caso mais singular, é assim que devemos entender Odradek (A Preocupação do Pai de Família), que é ao mesmo tempo um membro da família e um ser do mundo inorgânico.

Nos termos de Benjamin, estamos aqui diante de um "mundo primitivo"21 esquecido pela humanidade. Esse mundo primitivo é cosmológico na medida em que não antecede apenas o domínio da lei escrita, mas o próprio domínio da ordenação dos seres. Nas palavras de Benjamin:

Nenhuma [das criaturas de Kafka, R.F.] tem o seu lugar fixo, o seu contorno fixo, que não seja intercambiável: nenhuma delas não faz parte de uma ascensão ou de uma queda; nenhuma não se pode trocar por seu inimigo ou vizinho; nenhuma não está profundamente esgotada e, no entanto, no início de uma longa jornada. Não é possível falar aqui em ordens e hierarquias. ${ }^{22}$

Em relação à ideologia do progresso - traço principal do tempo histórico moderno - a literatura de Kafka apresenta uma negação radical. Uma recusa mais radical que a de

${ }^{18}$ Idem, p. 412.

${ }^{19}$ KAFKA, Franz. O Processo. Trad. Modesto Carone. São Paulo: Cia. das Letras, 1998, p. 9. Romane und Erzählungen. Köln: Parkland, 1998, p. 431.

${ }^{20}$ Apud BENJAMIN, Walter. Gesammelte Schriften II-2. Frankfurt (M): Suhrkamp, 1991, p. 412.

${ }^{21}$ Idem, p. 412. Ao traduzir Vorwelt por "pré-história", S. P. Rouanet negligencia um vínculo importante entre o mundo primitivo e o tempo cosmológico. Cf. BENJAMIN, Walter. Obras Escolhidas Vol. 1. São Paulo: Brasiliense, 1985, pp. 140 e 158.

22 BENJAMIN, Walter. Gesammelte Schriften II-2. Frankfurt (M): Suhrkamp, 1991, p. 415. 
Baudelaire, pois Kafka não nega apenas a teoria moderna do progresso como telos da história, mas o progresso tout court, isto é, a própria idéia de que é possível distinguir entre civilização e barbárie. A família kafkiana, composta de animais, humanos e até mesmo um ser inorgânico, impele o escritor a desnudar "o lado de baixo" da história:

Seguindo o imperativo dessa família, ele rola o bloco dos acontecimentos históricos, como Sísifo rola o rochedo. Com isso, ocorre que o seu lado de baixo vem à luz. Ele não é agradável de se ver. Mas Kafka é capaz de suportar sua visão. [...] A época em que Kafka vive não significa para ele nenhum progresso em comparação com os começos primordiais. Seus romances se passam num mundo pantanoso. A criatura lhe aparece no estágio que Bachofen caracterizou como hetaírico. ${ }^{23}$

A peculiaridade das parábolas kafkianas é um dos elementos centrais dessa interpretação. No ensaio de 1934, a parábola é vista através de uma analogia. Seu objetivo, como o dos gestos e imagens, é a produção de "reflexões intermináveis" ${ }^{24}$. Desse modo, a parábola kafkiana é o desdobramento de uma questão, mas é um desdobramento (Entfaltung) especial:

A palavra "desdobrado" é [...] de duplo sentido. Assim como o botão se desdobra na flor, o barco de papel dobrado, que nós ensinamos as crianças a fazer, desdobra-se na folha lisa. Essa segunda forma de "desdobramento" adapta-se propriamente à parábola, ao prazer do leitor de torná-la lisa, de modo que o seu significado fique sobre a palma da mão. Mas as parábolas de Kafka desdobram-se no primeiro sentido, ou seja, como o botão se desdobra na flor. ${ }^{25}$

Um processo de "abertura" da narrativa afasta as parábolas kafkianas do âmbito didáticoreligioso, aproximando-as da escrita propriamente literária (Dichtung). No entanto, elas não podem ser consideradas narrativas, no sentido específico de "O Narrador" (1936), nem literatura "pura" - no sentido que geralmente se dá à fórmula "poesia pura", no simbolismo. No ensaio sobre Leskov, embora as narrativas apresentem um não-acabamento constitutivo, que torna possível a sua reinserção em novos contextos, existe sempre uma possibilidade de adaptação da "moral da história" no sentido de um conselho para uma situação presente. Em Kafka, essa possibilidade desaparece. Se é verdade que "elas são arranjadas de tal modo que se pode citá-las e narrá-las visando uma explicação", ${ }^{26}$ entretanto, nós não possuímos a doutrina que deveria explicá-las.

A obra de Kafka está perpassada por "poderes primitivos" 27 que, no presente, atuam de modo secreto, uma vez que não se tem uma memória deles. Os animais de Kafka seriam ancestrais longínquos e esquecidos. ${ }^{28} \mathrm{O}$ corpo, analogamente, seria um esquecido país estrangeiro. ${ }^{29} \mathrm{O}$ estágio "hetaírico" descrito por Bachofen não desapareceu inteiramente:

\footnotetext{
${ }^{23}$ Idem, p. 428.

${ }^{24}$ Idem, p. 420.

${ }^{25}$ Ibidem.

${ }^{26}$ Ibidem.

${ }^{27}$ No original, vorweltlichen Gewalten. Idem, p. 426-427.

${ }^{28}$ Idem, p. 430.

${ }^{29}$ Idem, p. 431.
} 
"se esse estágio está esquecido, isso não quer dizer que ele não se manifeste no presente. Pelo contrário: ele está presente por meio desse esquecimento." ${ }^{30} \mathrm{Um}$ dos objetivos da obra de Kafka seria, portanto, o combate desse esquecimento do esquecimento, desnudando os poderes primitivos e mostrando a sua atividade oculta.

Na célebre carta de 12 de junho de 1938, endereçada a Scholem, Benjamin define esse co-pertencimento entre passado e presente, utilizando-se de uma metáfora geométrica:

A obra de Kafka é uma elipse cujos focos muito afastados um do outro são determinados, por um lado, pela experiência mística (que é sobretudo a experiência da tradição) e, por outro, pela experiência do homem das grandes cidades modernas. ${ }^{31}$

A elipse, com seus dois focos, é a imagem de um mundo cujo eixo central está partido. Um mundo dual, cujos centros afastados, isto é, esquecidos um do outro, são a tradição religiosa e a grande cidade. Em termos benjaminianos, tal mundo só pode ser pensado como um encontro mais ou menos secreto entre passado e presente. Por isso a percepção desse encontro não é imediatamente acessível a qualquer um. Ela pressupõe "uma experiência [Erfahrung] que vai mais fundo do que aquela do cidadão mediano" e que Kafka descreve como "um enjôo marítimo em terra firme". 32

Essa experiência nauseante acompanha Josef K. ao longo de toda a sua desditosa aventura. Mas ele não é capaz de assumi-la totalmente. Se o seu crime oculto é o esquecimento do esquecimento - como supõe Benjamin, a partir da leitura de Willy Haas ${ }^{33}$-, ele não chega nunca a ultrapassar o limiar da lembrança. $O$ mundo primitivo aparece-lhe na forma de um mundo "deslocado", "deformado" ou "desfigurado" (entstellt), ${ }^{34}$ do qual ele não pode extrair a forma original. Ele é incapaz de reconhecer que as forças arcaicas são simultaneamente forças atuais. O medo que ele experimenta, e que está presente em todo o livro, decorre de uma incapacidade de reconhecimento. Nas palavras de Benjamin, numa conferência radiofônica de 1931 ("Franz Kafka - Durante a Construção da Muralha da China"): "Esse medo [...] é ao mesmo tempo e em igual medida medo do mais que antigo, do imemorial, e medo do mais próximo, do que está surgindo no exato momento." 35

É nesse sentido que Benjamin interpretará o "personagem" Odradek, um dos mais radicais produtos da escrita de $\mathrm{Kafka}^{36}$. Ele será caracterizado da seguinte forma: "O mais

\footnotetext{
${ }^{30}$ Idem, p. 428.

${ }^{31}$ BENJAMIN, Walter. Gesammelte Briefe VI. Frankfurt (M): Suhrkamp, 2000, p. 110.

${ }^{32}$ BENJAMIN, Walter. Gesammelte Schriften II-2. Frankfurt (M): Suhrkamp, 1991, p. 428.

${ }^{33}$ Idem, p. 429.

${ }^{34}$ Idem, p. 431 e 432.

${ }^{35}$ Idem, p. 681.

36 "À primeira vista ele tem o aspecto de um carretel de linha achatado e em forma de estrela, e com efeito parece também revestido de fios; de qualquer modo devem ser só pedaços de linha rebentados, velhos, atados uns aos outros, além de emaranhados e de tipo e cor os mais diversos. Não é contudo apenas um carretel, pois do centro da estrela sai uma varetinha e nela se encaixa depois uma outra, em ângulo reto. Com a ajuda desta última vareta de um lado e de um dos raios da estrela do outro, o conjunto é capaz de permanecer em pé como se estivesse sobre duas pernas". Kafka descreve ainda o seu riso como "um farfalhar de folhas secas" e "um riso como só se pode emitir sem pulmões". KAFKA, Franz. Um Médico Rural. Trad. Modesto Carone. São Paulo: Brasiliense, 1999, p. 43-44. Romane und Erzählungen. Köln: Parkland, 1998, p. 735-736.
} 
singular bastardo, que o mundo primitivo em Kafka produziu junto com a culpa, é Odradek." Ou ainda: "Odradek é a forma que as coisas assumem no esquecimento. Elas são deformadas." Como um dos lugares que ele habita é o sótão, Benjamin estabelece um paralelismo entre o remexer das coisas velhas e esquecidas e o julgamento que envolve Josef K.:

O sótão é o lugar dos objetos descartados e esquecidos. A obrigação de comparecer ao tribunal evoca talvez o mesmo sentimento que a obrigação de remexer arcas antigas, deixadas no sótão durante anos. Se dependesse de nós, adiaríamos a tarefa até o fim dos nossos dias, do mesmo modo que K. acha que seu documento de defesa "poderá um dia ocupar sua inteligência senil, depois da aposentadoria". ${ }^{38}$

Embora Benjamin não o diga explicitamente, sua leitura sugere que o processo contra Josef $K$. assemelha-se a uma peripécia trágica em torno da rememoração. A violência do tribunal, que tenta forçá-lo a recordar, é tão impotente quanto os seus próprios esforços para escapar à punição. No primeiro caso, a corrupção e a confusão dos representantes da lei demonstram claramente o quanto eles estão afastados da genuína justiça. No segundo, é evidente que a defesa de K. enreda-se completamente nos mecanismos caóticos do tribunal. O processo não é nunca uma rememoração, uma reflexão, um juízo, mas apenas uma distribuição arbitrária de culpas, penas e poderes. Em outras palavras, há um esquecimento universal, pertencente à própria essência do cosmos kafkiano. Uma vez que a rememoração fracassa, que o anti-herói e seus juízes seguem todas as estações do processo, mas não chegam jamais à explicitação da culpa arcaica, Josef $\mathrm{K}$. deve pagar com a sua vida uma dívida em relação ao esquecimento. Mas essa dívida não é só dele; ela atravessa todo o cortejo das criaturas. Por isso, logo após a sua execução, lemos a frase lapidar: "Era como se a vergonha devesse sobreviver a ele." ${ }^{39}$

Para Benjamin, a questão política em Kafka será mal considerada se o esquecimento de Josef K. for pensado apenas como um fenômeno individual. Essa é uma diferença significativa em relação à sua interpretação de Proust. Em vez de localizar em outro ponto como a poesia de Baudelaire e a história materialista - uma dimensão histórico-social da memória involuntária, para então contrapô-la ao solipsismo da lembrança proustiana, Benjamin situará na própria obra de Kafka o tema do esquecimento coletivo. Que a obra de Kafka apresente um interesse profundamente político, é evidente a qualquer leitor atento. Se O Processo não fosse suficiente para deixar isso claro, bastaria ler O Castelo, $\mathrm{Na}$ Colônia Penal, Uma Mensagem Imperial, etc. A novidade da leitura de Benjamin está em inserir a discussão do significado político da obra no âmbito do problema da memória e do esquecimento, criando assim as condições para uma comparação com Proust, Baudelaire e a historiografia materialista. Nesse sentido, ele vai muito além da idéia de Willy Haas sobre a amnésia de Josef K., transferindo o esquecimento para o centro da obra kafkiana.

O esquecimento está aqui, portanto, mais próximo da rememoração (Eingedenken) do que da lembrança (Erinnerung). A escrita de Kafka significa um modo coletivo de "remexer"

${ }^{37}$ BENJAMIN, Walter. Gesammelte Schriften II-2. Frankfurt (M): Suhrkamp, 1991, p. 431.

${ }^{38}$ BENJAMIN, Walter. Obras Escolhidas Vol 1. Trad. Sérgio Paulo Rouanet. São Paulo: Brasiliense, 1985, p.158. Gesammelte Schriften II-2. Frankfurt (M): Suhrkamp, 1991, p. 431.

${ }^{39}$ KAFKA, Franz. O Processo. Trad. Modesto Carone. São Paulo: Cia. das Letras, 1998, p. 278. Romane und Erzählungen. Köln: Parkland, 1998, p. 707. 
nos objetos esquecidos. Mas ela distingue-se da rememoração descrita nas teses "Sobre o Conceito da História" (1940) pelo fato de apresentar uma versão por assim dizer "fracassada" dessa atividade de rememoração. O tema do "fracasso" de Kafka dá margem a um dos mais interessantes comentários de Benjamin. O testamento de Kafka, com a determinação de que sua obra fosse destruída, é para ele um indício de que Kafka considerava malograda a sua tentativa literária, naquilo que ela possuía de mais específico:

Fracassada foi sua grandiosa tentativa de transformar a literatura em doutrina [Lehre], devolvendo-lhe, enquanto parábola, a solidez e a discrição que, em face da razão, apareciam-lhe unicamente como as adequadas. Nenhum escritor seguiu tão rigorosamente o "tu não deves construir imagens". ${ }^{40}$

Esse suposto fracasso parece derivar de um antigo preceito moral. Esse último, no entanto, surge "em face da razão", isto é, ele depende mais da iconoclastia do iluminismo do que da proibição de imagens propriamente dita (Exxodo 20,4-5). Mas seria um erro interpretar esse leitmotiv religioso de modo literal. A iconoclastia é aqui a atitude própria de uma narrativa que abandonou tanto a religiosidade tradicional quanto a racionalidade moderna. De fato, num outro momento do ensaio, Benjamin caracterizará as criações de Kafka como "contos de fada para dialéticos" (Märchen für Dialektiker), ou seja, como uma demonstração dos poderes "mágicos" da narrativa no desencantamento do próprio universo mítico. ${ }^{41}$

$$
* * *
$$

Em seu fluxo em direção à barreira da dor, o fracasso de Kafka é um êxito singular. Se a corrente da narrativa choca-se com a barreira e a vence, isso ocorre, em primeiro lugar, porque ela foi capaz de enfrentá-la, de encarar face a face o encontro assustador do mais moderno e do mais arcaico, na desumanização que se apresenta em todas as esferas da vida contemporânea. O primeiro gesto kafkiano consiste, portanto, em desestetizar radicalmente a escrita, de modo que ela possa co-habitar com a desumanização.

Mas o fluxo narrativo vence a dor, igualmente, porque ele é capaz de interromper a sua própria tarefa rememorativa. Ele não substitui o esquecimento dos poderes primitivos por uma rememoração totalizante, de modo a pretender apropriar-se do passado plenamente, passando dos poderes arcaicos a uma humanidade integralmente civilizada. Para que o enfrentamento do mito não produza uma nova mitologia da razão, é preciso que a narrativa saiba também esquecer-se a si própria, para dissolver-se no "mar do feliz esquecimento". O segundo gesto kafkiano é, portanto, uma espécie de estetização da doutrina. Um movimento por meio do qual a sabedoria possa abandonar o fardo das grandes palavras, o rigor excessivo da antiga moral, para estabelecer uma relação nova, e favorável, com o não-humano no homem.

Nesse sentido, a tarefa da escrita kafkiana é semelhante à de um dos personagens mais marcantes que ela produziu: o "novo advogado". Embora externamente ele pareça um homem comum, qualquer freqüentador de corridas de cavalos pode admirar o modo como ele sobe os degraus do fórum. Ele já foi o cavalo de batalha de Alexandre da Macedônia, mas hoje, na ausência das grandes viagens e dos grandes significados, sua atividade "épica" consiste no trato lúdico com a escrita e no estudo sereno da tradição:

${ }^{40}$ BENJAMIN, Walter. Gesammelte Schriften II-2. Frankfurt (M): Suhrkamp, 1991, p. 427-428.

${ }^{41}$ Idem, p. 415. 
Já naquela época as portas da Índia eram inalcançáveis, mas a direção delas estava assinalada pela espada do rei. Hoje as portas estão deslocadas para um lugar completamente diferente, mais longe e mais alto; ninguém mostra a direção; muitos seguram espadas, mas só para brandi-las; e o olhar que quer segui-las se confunde. Talvez por isso o melhor realmente seja, como Bucéfalo fez, mergulhar nos códigos [Gesetzbücher]. Livre, sem a pressão do lombo do cavaleiro nos flancos, sob a lâmpada silenciosa, distante do fragor da batalha de Alexandre, ele lê e vira as folhas dos nossos velhos livros. ${ }^{42}$

\title{
A
}

\begin{abstract}
A B STRACT
What is the meaning of writing in Benjamin's motif of history as a redemption of the past? In the essay on Kafka (1934), the problem of the aesthetic character of the writing of history is associated with the issue of the value of truth ("doctrine") of fiction. Between the two there starts to come out a dialectics between remembering and forgetting, in which writing transforms narrative into a kind of memory which, acting against itself, achieves the "sea of happy forgetting".
\end{abstract}

KEYWORDS

Benjamin, Kafka, Writing, Doctrine, Remembering, Forgetting.

\section{REFERÊNCIAS BIBLIOGRÁFICAS}

BENJAMIN, Walter. Gesammelte Schriften. Frankfurt (M): Suhrkamp, 1991. 7 Volumes. . Gesammelte Briefe. Frankfurt (M): Suhrkamp, 1995/2000. 6 volumes. . Obras escolhidas Vol. 1. Trad. Sérgio Paulo Rouanet. São Paulo: Brasiliense, 1985.

CALDERÓN. O Grande teatro do mundo. Trad. Maria de Lourdes Martini. Rio de Janeiro: Francisco Alves, 1998.

DEURING, Dagmar. Vergiss das Beste nicht! In: Walter Benjamins Kafka-Essay: Leben, Schreiben, Erfahren. Würzburg: Königshausen/Neumann, 1994.

GAGNEBIN, Jeanne-Marie. História e narração em Walter Benjamin. São Paulo: Companhia das Letras, 1994.

KAFKA, Franz. O processo. Trad. Modesto Carone. São Paulo: Companhia das Letras, 1998. . Romane und Erzählungen. Köln: Parkland, 1998. . Um médico rural. Trad. Modesto Carone. São Paulo: Companhia das Letras, 1999.

MÜLLER, Bernd. Denn es ist noch nicht geschehen. In: Walter Benjamins Kafka-Deutung. Köln: Böhlau, 1996.

RÜHLE, Günter. Theater in unserer Zeit. Frankfurt (M): Suhrkamp, 1980.

${ }^{42}$ KAFKA, F. Um Médico Rural. Trad. Modesto Carone. São Paulo: Brasiliense, 1999, p. 11-12. Romane und Erzählungen. Köln: Parkland,1998, p. 709-710. 